\title{
Gastroenteritis Outbreaks in Greece
}

\author{
Rengina Vorou", George Dougas, Kassiani Gkolfinopoulou and Kassiani Mellou
}

Hellenic Center for Disease Control and Prevention (HCDCP), Ministry of Health and Social Solidarity, Athens, Greece

\begin{abstract}
The outbreaks notified to both local Human Public Health (HPH) and Hellenic Center for Diseases Control and Prevention (HCDCP), from $1^{\text {st }}$ January 2005 to $31^{\text {st }}$ December 2007, were analyzed via the comprehensive forms filled in by HCDCP professionals. The attack rate was similar to other European countries $0.5 / 100000$ population. A total of 160 outbreaks were reported, 36\% domestic, $42 \%$ restaurant/pastry shop/hotel restaurant/catering service (RPHC), 3\% school/day care and 3\% hospital/nursing homes based. Among them $84.4 \%$ were foodborne, $5.9 \%$ with person to person transmission (PTP), 7.1\% with both routes, and 2.6\% waterborne. Stool samples and food specimens from foodborne outbreaks were collected. The pathogen was identified in $76 \%$, among which, $63 \%$ was salmonella spp, associated with raw shell eggs and chicken, shorter duration and higher attack rates outbreaks, and $4.5 \%$ norovirus, the latter with unidentified setting in the community, and mainly with PTP transmission. Continuous food safety education will contribute to the already existing governmental legislation and guidance and relevant public health measures. Routine use of existing diagnostic facilities and techniques and timely notification will further enable the public health stakeholders to diagnose and control gastroenteritis outbreaks promptly.
\end{abstract}

Keywords: Foodborne outbreak, gastroenteritis, waterborne outbreak, salmonella spp, Norovirus, human public health, veterinary public health collaboration.

\section{INTRODUCTION}

Foodborne disease is among the most widespread health problems worldwide even though its actual burden cannot be estimated with accuracy due to underreporting [1, 2]. Surveillance of foodborne outbreaks facilitates their timely detection, investigation, and control.

In Greece, the national surveillance system for communicable diseases was re-organized and improved in the context of the preparation for the Olympic Games 2004. This was necessary as the pre-existing notifiable disease list was outdated, reporting was on a monthly basis, many physicians disrespected surveillance and their participation was low. As a result of these reasons we cannot attempt any comparison with previous data derived by the pre-existing surveillance system. The mandatory notification system, the laboratory reporting system and the primary care sentinel physician system comprise since then the novel surveillance system. Infectious diseases experts from all over Greece participated in a prioritization survey, and a new list of notifiable diseases was defined, including the notification of foodborne outbreaks [3].

The characteristics of the outbreaks notified from $1^{\text {st }}$ January 2005 to $31^{\text {st }}$ December 2007, regarding the settings, the pathogens, the transmission routes, the methods of investigation, and the suspected foods are presented in this study. The aim of this analysis is to deduce conclusions for the improvement of surveillance, investigation (microbiologic and environmental components), intervention, and if

*Address correspondence to this author at the Hellenic Center for Disease Control and Prevention (HCDCP), Ministry of Health and Social Solidarity 34, Ipirou str, Chalandri, 15 231, Athens, Greece; Tel: (+30)210 8899 041, (+30)6976 1780 74; Fax: (+30)210 8818 868; E-mail: vorou@keelpno.gr indicated to affect national policies regarding foodborne/ waterborne outbreaks.

\section{METHODS}

\section{Material}

The study analyses the characteristics of all gastroenteritis outbreaks that were reported to the Hellenic Center for Disease Control and Prevention (HCDCP), with date of onset of the first case between 1 January 2005 and 31 December 2007.

The outbreak definition applied for foodborne/waterborne outbreaks was: «occurrence of at least two cases with common symptoms, usually gastrointestinal, which can be attributed to the consumption of a common food item or water of the same origin or to a common activity» [4-8]. There is not any prerequisite of a suspected meal, or a suspected food, or a positive food culture. This definition via the term "common activity" increases the sensitivity of the surveillance system and depicts a variety of routes of transmission, apart from food and water.

\section{Surveillance}

Surveillance is performed via mandatory notification of any cluster of gastroenteritis cases as mentioned above. Hospital outpatient and inpatient departments, health centers, distant general practices notify both the corresponding local human public health department $(\mathrm{HPH})$ (one in each of the 52 prefectures) and the HCDCP, Athens, Greece.

\section{Data and Sample Collection (Epidemiologic and} Microbiologic Investigation)

1. Local HPH fills in the mandatory notification form (line listing) including the results of environmental investigation, human (patient and foodhandlers') stool 
cultures in local laboratories, and those of cooked food remnants or others found on the day of inspection, cultured in the Central Public Health Laboratory, HCDCP.

2. HCDCP scientists provide upon request a structured questionnaire for analytic epidemiologic analysis to the local HPH, analyze the data, supervise the microbiologic investigation and register all data in a dedicated database. The results are provided to the Department of Zoonoses, Ministry of Rural Development and Food on a regular basis.

3. The local veterinary public health directorates (VPH) (one in each of the 52 prefectures) are notified, whenever the collection of raw materials of animal origin (i.e. meat, milk, cheese) for toxin detection and culture in veterinary reference laboratories is indicated. On these occasions we are provided with investigation results upon request.

4. The local medical microbiology laboratories most commonly perform stool cultures for salmonella spp, shigella spp less often for EHEC (O157), mainly on selective media, ova cyst parasites (OCP) microscopy for Entamoeba histolytica and Giardia lamblia. Virologic investigation and detection of toxin of Staphylococcus aureus, Escherichia coli, Bacillus cereus, Clostridium perfrigens are not performed in local level routinely. Campylobacter culture, investigation for Cyclospora cayettanensis and Crypotosporidium parvum, Serotyping of Salmonella spp, Shigella spp, and verification of identical strains via Pulse Field Gel Electoctrophoresis, Norovirus testing of human specimens, food and water culture, are performed in specific University, National School of Public Health, HCDCP or other leading Hospitals and dedicated laboratories upon request.

\section{Criteria for Investigation}

The decision for further investigation i.e. microbiologic, epidemiologic, environmental (food sampling, hygiene standards) was based on the considerable number of cases, timeliness of the report (early report), severe gastrointestinal disease, and unidentified route of transmission [9]. When human cultures test positive distribution of questionnaires and collection of samples from food handlers are conducted while visit to the place of meal is frequently surpassed. In certain prolonged extended outbreaks, in place investigation is conducted by a team of HCDCP experts.

\section{Data Analysis}

All data in comprehensive forms that are completed by UZFD, HCDCP, are recorded to a common database, and analyzed, using EpiInfo3.3.2.

The duration of the outbreak is the period between the date of onset of symptoms for the first case and the date of onset of symptoms for the last case. The duration of the outbreak was registered as one day when all patients fell ill on the same day.

The attack rate was the percentage of exposed persons who developed symptoms during the outbreak. The total numbers of people exposed to the particular food, water source or involved in the activity which was the cause for the outbreak were reported by the local public health authorities and they were not always available as indicated in Table $\mathbf{1 .}$

Table 1. Number of Cases, Attack Rate and Median Duration of Outbreaks by Setting, Transmission Route and Pathogen

\begin{tabular}{|c|c|c|c|c|c|c|c|c|c|}
\hline & & $\begin{array}{l}\text { Median } \\
\text { Number } \\
\text { of Cases }\end{array}$ & $\begin{array}{c}\text { Range of } \\
\text { Number of } \\
\text { Cases } \\
\text { (Min-Max) }\end{array}$ & $\begin{array}{c}\text { N } \\
\text { with } \\
\text { Known } \\
\text { Attack } \\
\text { Rate }\end{array}$ & $\begin{array}{c}\text { Median } \\
\text { Attack } \\
\text { Rate } \\
(\%)\end{array}$ & $\begin{array}{c}\text { Range } \\
\text { Attack } \\
\text { Rate } \\
\text { (Min- } \\
\text { Max) }\end{array}$ & $\begin{array}{c}\mathbf{N} \\
\text { with } \\
\text { Known } \\
\text { Duration }\end{array}$ & $\begin{array}{c}\text { Median } \\
\text { Duration } \\
\text { (Days) }\end{array}$ & $\begin{array}{c}\text { Range } \\
\text { Duration } \\
\text { (Min- } \\
\text { Max) }\end{array}$ \\
\hline Overall & $\begin{array}{l}160 \text { with known number of } \\
\text { cases }\end{array}$ & 5 & $2-702$ & 40 & 59 & $2-100$ & 129 & 1 & $1-76$ \\
\hline Setting & 136 with known setting & & & & & & & & \\
\hline $\begin{array}{l}\text { Restaurant / pastry shop/ } \\
\text { hotel/catering (RPHC) }\end{array}$ & 57 & 8 & $2-180$ & 17 & 50 & $5.3-100$ & 49 & 1 & $1-20$ \\
\hline School / day Care & 4 & 23 & $3-50$ & 0 & & & 4 & 1 & $1-2$ \\
\hline Hospital / nursing homes & 4 & 44 & $2-133$ & 1 & 57 & & 3 & 3 & $1-5$ \\
\hline Transmission route & $\begin{array}{l}154 \text { with known transmission } \\
\text { route (unknown in 6) }\end{array}$ & & & & & & & & \\
\hline Food $130(84.4 \%)$ & 130 & 4.0 & $2-180$ & 33 & 67 & $5.3-100$ & 106 & 1 & $1-20$ \\
\hline Water $4(2.6 \%)$ & 3 with known number of cases & 365 & $43-702$ & 1 & 2.3 & & 3 & 14 & $9-31$ \\
\hline \multicolumn{10}{|l|}{ Pathogen } \\
\hline Salmonella spp. & 101 & 4 & $2-180$ & 24 & 71 & $5.3-100$ & 78 & 1 & $1-11$ \\
\hline Norovirus & 7 & 37 & $20-702$ & 2 & 46 & $33-46$ & 5 & 4 & $4-26$ \\
\hline
\end{tabular}




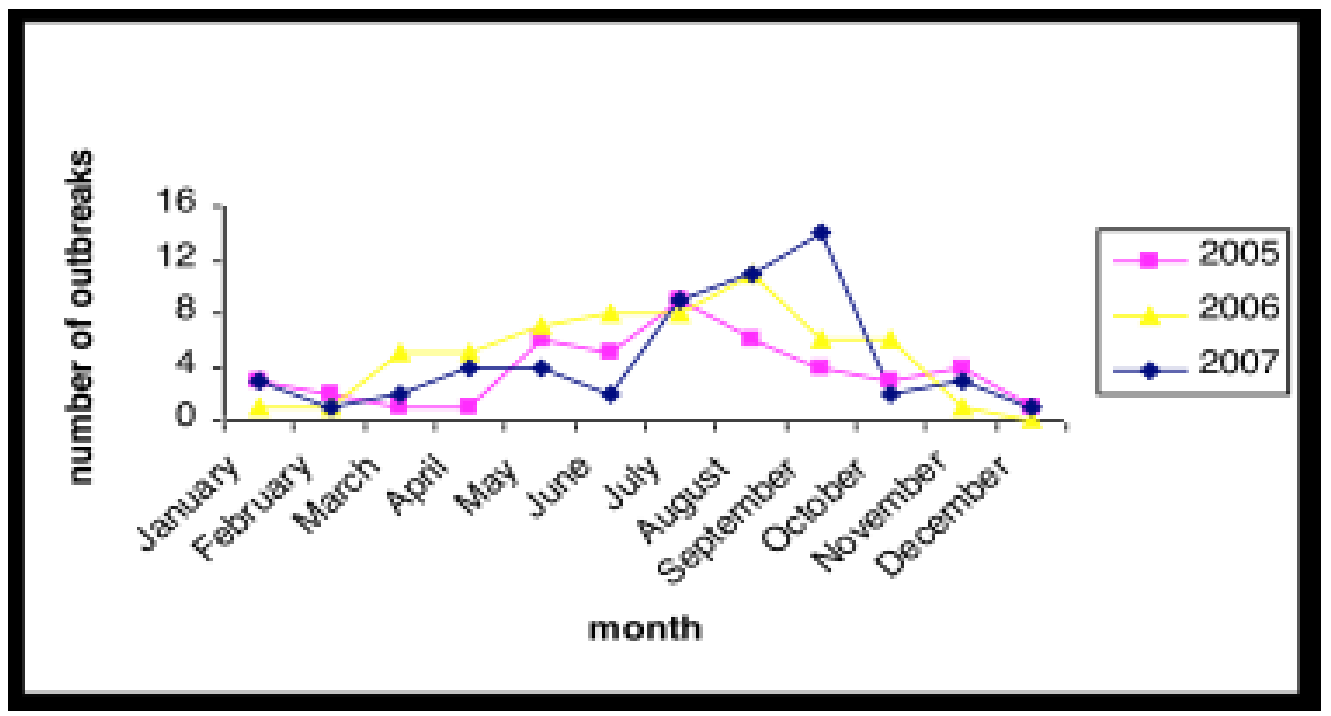

Fig. (1). Seasonal distribution of foodborne and waterborne outbreaks in Greece 2005-2007.

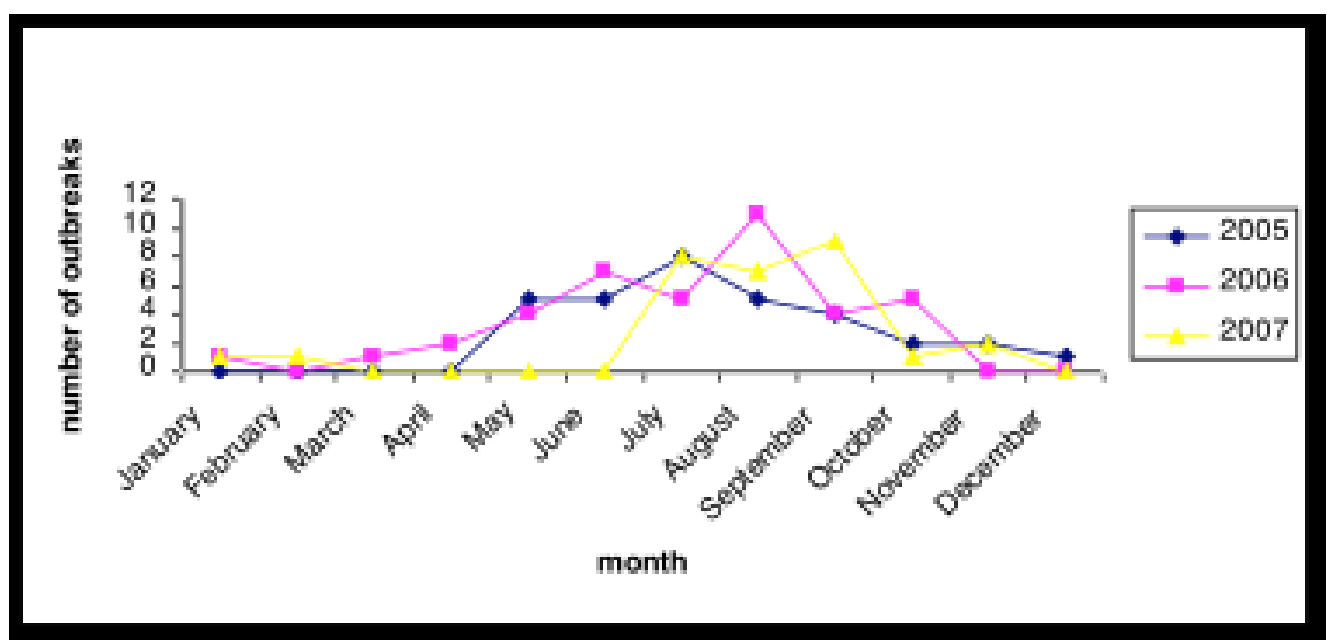

Fig. (2). Seasonal distribution of foodborne and waterborne outbreaks caused by Salmonella spp. in Greece from 2005 through 2007.

\section{RESULTS}

\section{Outbreaks: Seasonal Pattern, Notification, Setting}

During this period of time a total of 160 outbreaksinvolving 3467 cases of gastroenteritis-were reported across the country. There was a clear seasonal pattern with a high frequency of outbreaks during July, August and September, similar to the Salmonella pattern (Figs. 1, 2).

We received mandatory notification form for gastroenteritis outbreaks from the local HPH for $16(10 \%)$ and from health care units for 139 outbreaks (87\%). No form was available for one outbreak notified from the patients, three from mass media and one from the European Network Enter-net.

Fifty four percent of all cases were females, and 18\% were children (age $\leq 14$ years), 2396 (69\%) patients visited a doctor, 862 of them (25\%) required hospitalization, and there were no fatalities.

The mean annual incidence of outbreaks was 0.5/100 000 population. The mean annual regional incidence exhibited minor variation (range from zero to one per $100 \quad 000$ population).
The domestic were 49, the restaurant/pastry shop/hotel restaurant/catering service (RPHC) were 57, the school/day care were 4 and the hospital/nursing homes were 4 (Table 1). The attack rate overall varied from 2 to $100 \%$ with a median $59 \%$. The duration of the outbreaks is known for 129 , varied from 1 to 76 days, median duration 1 day.

\section{Analysis by Causative Agent, Transmission Route, Setting}

Transmission from food occurred in $130(84.4 \%$ of outbreaks with known transmission route) (Table 1) outbreaks; 49 domestic, 55 RPHC, 4 school as well as in 4 hospital/nursing homes, whereas in one RPHC food combined with PTP transmission occurred (Table 2). Ninety nine of the 130 foodborne outbreaks $(76 \%)$ were attributed to salmonella spp and zero to norovirus. For domestic and $\mathrm{RPCH}$ the most common food item was raw shell eggs in the $38 \%$ and $39 \%$ respectively, followed by poultry in the $28 \%$ and $22 \%$ respectively, and the most common pathogen was salmonella spp (Table 3).

Tap water was considered to be the vehicle in 4 outbreaks $(3 \%)$, in three of them tap or spring water were sent for culture, in 1 norovirus was isolated from water as 
Table 2. Route of Transmission in domestic, Restaurant / Pastry Shop/ Hotel/Catering, School/Day Care, Hospital/Nursing Setting

\begin{tabular}{|c|c|c|c|c|c|}
\hline Setting of Outbreak ${ }^{a}$ & $\begin{array}{l}\text { With Known Mode of } \\
\text { Transmission N }\end{array}$ & PTP & Food and PTP & Food Alone & Water \\
\hline $\begin{array}{l}\text { Domestic } \\
\mathrm{N}=49(36 \%)\end{array}$ & 49 & 0 & 0 & 49 & 0 \\
\hline Restaurant / pastry shop/ hotel/catering N=57 (42\%) & 56 & 0 & 1 & 55 & 0 \\
\hline School / day Care N= $4(3 \%)$ & 4 & 0 & 0 & 4 & 0 \\
\hline $\begin{array}{l}\text { Hospital / nursing home } \\
\mathrm{N}=4(3 \%)\end{array}$ & 4 & 0 & 0 & 4 & 0 \\
\hline $\begin{array}{l}\text { Overall with known setting } \\
\mathrm{N}=136(100 \%)\end{array}$ & 113 & 0 & 1 & 112 & 0 \\
\hline
\end{tabular}

${ }^{\mathrm{a}}$ The most frequent settings are mentioned.

well as from human samples, in two no pathogen was identified in water sample (in one norovirus was detected in human samples only) and in one no water sample was obtained. In three the number of cases ranging from 43 to 702 cases with a median of 365 cases, the attack rate was measurable in one set to $2.3 \%$, the duration was ranging from 9 to 31 days, 14 days median (Table $\mathbf{1}$ ).

Person to person (PTP) transmission was identified for the 9 outbreaks ( $6 \%$ of the known transmissions) with no specific setting, among which norovirus was detected in two, HAV in two, rotavirus in one, $S$. virchow in one and EHEC in one outbreak, all from human samples (Tables 1 and 2). Similarly, in the $11(7 \%)$ with food transmission combined with person to person (Food+PTP) transmission only the community setting and not a particular setting was incriminated and the pathogens diagnosed in humans were HAV in 4, Norovirus in 3, and S. sonnei in one (Tables 1 and 2).

There was not animal to human transmission. Six outbreaks appeared with unexplained mode of transmission (Table 2). In household, RPHC, school/day care and hospital/nursing homes dominated the food transmission (Table 2). In unspecified, community setting dominated the PTP and PTP combined with food transmission (Table 2).

The causative agent was detected in 121 (76\%) outbreaks with salmonella spp. (Figs. 1, 2) identified as the responsible pathogen in $101(63 \%), 99$ of which due to food transmission (Tables $\mathbf{1}$ and 2), and Salmonella enteritidis the most frequent serotype (39 outbreaks, 24\%) in the overall and among 39 domestic, 46 RPHC, 4 school/day care and 4 hospital/nursing home outbreaks (Table 3). In 2007 an increased incidence of Salmonella muenchen occurred in Greece, with 10 patients from different geographic areas, and a tachini product and a tap water sample both from the same area to test positive for the pathogen with PFGE proving similar molecular type for all isolates. Among the 3467 outbreak-related cases, 851 (24.6\%) were caused by the seven norovirus outbreaks. Among these, two were due to PTP transmission, 3 with PTP + food transmission, all with food samples negative for norovirus, and 2 were waterborne. The setting for all was the community. In the 4 outbreaks caused by norovirus in the same area in four visiting school populations, stool samples were tested for the presence of the virus with a nested RT-PCR assay, using two sets of primers, which distinguish between genotype I or genotype II of norovirus [10]. All five samples were positive for norovirus type II. This result was confirmed by sequencing of the PCR product. The four schools norovirus outbreaks occurred during April 2007, compatible with seasonal pattern of the new variant of the genotype Lordsdale GGII.4 [11]. Norovirus triggered larger outbreaks than salmonella but salmonella depicted higher attack rates than norovirus. The outbreaks caused by water, were in the community setting, the two caused by Norovirus (one with water samples and one with human samples positive for norovirus), and the other two with unspecified pathogen.

Hepatitis A virus induced two outbreaks with 4 cases each in roma populations, two outbreaks with 2 cases each in prisoners, and two outbreaks with two cases each related to travel and camping.

\section{Analysis by Size, Attack Rate, and Duration of Outbreak}

The median size of outbreak in each setting reveals larger number in RPHC, followed by hospital /nursing homes and household outbreaks (Table 1). Eighty three (52\%) of the notified outbreaks included no more than five cases, whereas the largest outbreak, induced by norovirus, reached the total number of 702 cases.

Domestic outbreaks involved small numbers of exposed people, had small numbers of cases, ranging from 2 to 90 with a median of 3 , attack rate ranging from $50-100 \%$ with a median of $77.5 \%$, duration ranging from 1 to 5 days with a median of 1 day. RPHC outbreaks had 8 cases median number (range 2-180), the attack rate was lower ranging from $5.3-100 \%$ with a median of $50 \%$, and the duration 1 day (median) ranging from 1 to 20 days. In hospital/nursing home facilities the median number of cases was 44 ranging from 2 to 133, the attack rate was $57 \%$ in one, and the median duration 3 days (range 1-5 days). The attack rate was not possible to be assessed in school setting. The PTP transmission, food and PTP, and food transmission have median number of cases 12 (range 2-702), 11 (range 2-41), 4 (range 2-180), duration 6 (range 2-28), 5.5 (range 1-76), 1 (range 1-20) days respectively.

Salmonella spp. is followed by norovirus, with median number of cases 4 (range 2-180) and 37 (range 20-702) respectively, attack rate 71 (range 5.3-100) and 46 (range 33- 
Table 3 Pathogen in Domestic, Restaurant / Pastry Shop/ Hotel/Catering, School/Day Care, Hospital/Nursing Setting

\begin{tabular}{|c|c|c|c|c|c|}
\hline Salmonella spp. (All) & 101 & 39 & 44 & 4 & 4 \\
\hline (-S. Enteritidis) & (39) & (14) & (16) & (1) & (3) \\
\hline HAV & 6 & 0 & 0 & 0 & 0 \\
\hline Shigella sonnei & 1 & 0 & 1 & 0 & 0 \\
\hline Escherichia coli & 2 & 0 & 0 & 0 & 0 \\
\hline Rotavirus & 1 & 0 & 0 & 0 & 0 \\
\hline
\end{tabular}

${ }^{a}$ Numbers in columns do not sum up to the number in column (overall) because of other non mentioned settings.

46) respectively and duration 1 (range 1-11) and 4 (range 426) respectively.

\section{Type of Investigation Per Setting and Size of Outbreak}

Microbiology of human samples is the predominant investigation method for all settings followed by analytical epidemiological investigation in RPHC and hospital/nursing home settings (Table 4). In 139 outbreaks human specimens were collected, in 121 of which the pathogen was identified and in 13 no pathogen was found (Table 4).

Among the 49 domestic 45 had confirmed aetiology with human samples (92\%) (Table 4).

In 51 of the 57 RPHC there was confirmed etiology with human samples $(90 \%)$ and a cohort analytical epidemiological study was conducted in four outbreaks (Table 4). In $11(19 \%)$ food remnants or relevant batch samples were sent for culture and in $31(54 \%)$ the practices followed in the kitchen were inspected (Table 4). In the 3 of the 4 school/day care, stool samples were collected, hygiene standards examined and in one microbiology of food samples was demanded (Table 4).

Among hospital/nursing home outbreaks, in one a cohort analytical epidemiological study was conducted, in one more a case-control analytical epidemiological study was conducted, in all 4 human samples were collected and in two food sampling took place and hygiene standards were assessed.

A food item was suspected as the vehicle of transmission in 141 outbreaks (88\%), in 77 outbreaks $(48 \%)$ a food source was specified. In 67 (42\%) (Table 4) environmental investigation by the HPH took place and in $22(14 \%)$ food samples were sent for culture, only one tested positive for norovirus (althouth human faeces tested negative) (Table 4).

\section{Control Measures}

Control measures were taken for all outbreaks. Hygiene guidelines regarding hand washing, gloves, gowns in RPHC, in school/day care and hospital/nursing homes as well as advice to families were provided. Regarding Hepatitis A Virus (HAV), hygiene, education, and vaccination campaigns for the 2-18 years old were held by the HPH. The vaccine against Hepatitis A virus has been introduced free of charge for all children older than 2 years old in the country, on a voluntary basis, and it has been encouraged by HPH for roma populations, their classmates/neighbours as well as for all food handlers.

Table 4. Investigation Method

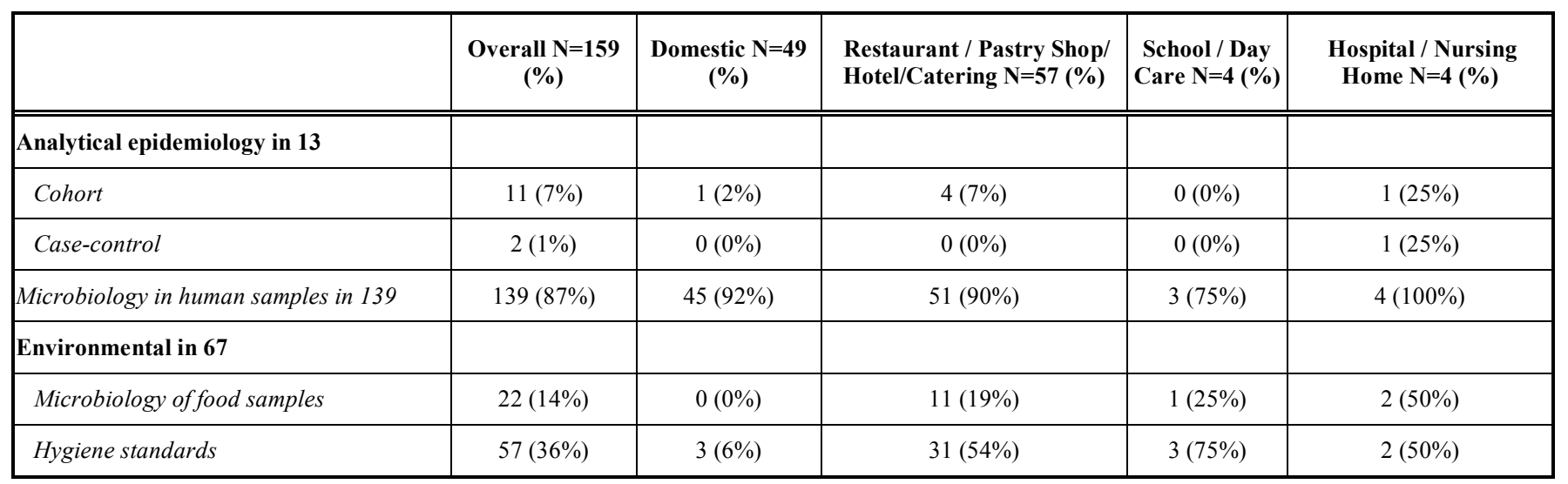




\section{DISCUSSION}

The re-organization of the surveillance system during the preparation for the Olympic Games 2004 resulted in the operation of multiple surveillance systems, the daily reporting of gastroenteritis ourbreaks, and the encouragement of the direct reporting to the HCDCP along with the reporting to the public health authorities of the respective prefecture.

From $1^{\text {st }}$ January 2005 to $31^{\text {st }}$ December 2007, 160 outbreaks with 3467 cases of gastroenteritis were notified, mainly in RPHC and households followed by school/day care and hospital/nursing homes. The mean annual incidence of outbreaks was $0.5 / 100,000$ population, which is within the range reported by other European countries [12, 13]. In all settings food is the most likely route of transmission and Salmonella the most commonly identified pathogen followed by norovirus. Among food and food+PTP $92 \%$ of the outbreaks were caused by bacteria and $8 \%$ by viruses.

Local VPH and Veterinary laboratories are further improving their collaboration with local HPH and HCDCP, an evolution which is necessary as the information flow was not prompt until recently. The HCDCP and the Veterinary Directorate of the Ministry of Agriculture and Food Affairs exchange data on a regular basis centrally and they have encouraged regular data flow in local level as well. A joint collaboration is in place regarding brucellosis in the context of a wide range mutual support between the two sectors in Greece.

Worldwide, underreporting is an undoubted parameter affecting the number of registered outbreaks, especially from community, schools, and hospitals $[1,2]$. In Greece this phenomenon is controlled by the three co-existing surveillance systems. Namely the mandatory notification system, is empowered by the laboratory reporting system and the primary care sentinel physician system, both of them revealing increased incidence and accelerating the notification. In hospitals the in-house expertise of infectious diseases specialists and medical microbiologists participating in the hospital infection control committees, render the role of HPH and HCDCP of minor importance during outbreak control, but delayed notification occurs as a result of our close collaboration with these committees. The reported numbers of hospital based gastroenteritis outbreaks represent the current situation. Outbreaks with PTP transmission $(5.9 \%)$ are not routinely notified except when attributed initially to a food vehicle. As investigation of human samples for campylobacter, Cyclospora cayetanensis and Cryptosporidium parvum is not a routine practice, and parasitic infections have long incubation period and mild symptoms, we cannot estimate the incidence of gastroenteritis caused by these pathogens.

The pathogen was detected in $76 \%$ of the outbreaks, in concordance with other European reports; this percentage varies from $41 \%$ in France to $78 \%$ in Portugal [13]. Similarly to other reports, Salmonella spp. was responsible for the majority of the outbreaks and Salmonella enteritidis was the most frequently identified serotype [14-19].

The seasonal pattern of gastroenteritis outbreaks coincides with that of salmonella outbreaks, with higher frequency during July to September due to high temperatures that favour the proliferation of bacteria in food. Regarding salmonella spp, raw shell eggs and food items containing raw shell egg were common vehicles $(38 \%)$, as in other countries $[12,14,16]$, followed by chicken $(25 \%)$. This indicates the need for further education of the public on how to achieve high hygiene standards i.e. heating and avoidance of cross contamination when raw shell eggs are used in food preparation.

Norovirus was implicated in foodborne outbreaks as a result of food contamination by infected food handlers [20]; cold-served foods such as a sweet in one outbreak and salad in others have been suspected as well [21, 22]. Being highly contagious [23], decontamination was required after vomiting, as aerosolized particles [23] are persistent in the environment [24]. We experienced extended outbreaks which were brought to an halt only after thorough decontamination of public accommodation and food preparation establishments or treatment of tap water. Food is not routinely tested for norovirus and there is need for establishment of these techniques and routine testing of human samples both being indispensable subsidiary to the outbreak investigation.

Bacteria are mostly foodborne whereas viruses person to person transmitted and/or via food. In 2005, 2006, 2007 the bacterial gastroenteritis accounted for the $92 \%, 91 \%, 79 \%$ of the outbreaks and viruses for the $8 \%, 9 \%, 21 \%$ of the outbreaks with known aetiology.

Domestic outbreaks were also recorded and analyzed for the first time, with their percentage estimated similar to other countries $[12,15,25]$, being attributed to unsafe foodhandling practices and indicating the need for further domestic food safety education of the public [26-28].

The delay of notification to local public health authorities and subsequently to the well trained inspectors of Food Safety Authorities and local Veterinary Public Health Authorities accounts for the limited number of outbreaks with incriminated foods available for sampling and testing. Therefore, there is imperative need that early notification and early sampling are achieved via an HPH VPH regular data exchange and integrated investigation activities. The problems encountered during investigation are similar to other Mediterranean countries of Europe [12, 13, 29].

Conclusively, the implementation of a mandatory notification system for gastroenteritis outbreaks has increased the awareness and motivation of physicians in reporting and public health officials in intervening but there is abundant ground for further improvement of the already successfully established HPH - VPH collaboration and outbreak investigation $[30,31]$ in Greece.

\section{REFERENCES}

[1] Kosek M, Bern C, Guerrant RL. The global burden of disease, as estimated from studies published between 1992 and 2000. Bull World Health Organ 2003; 81: 197-203.

[2] Mead PS, Slutsker L, Dietz V, et al. Food-related illness and death in the United States. Emerg Infect Dis 1999; 5: 607-25.

[3] Panagiotopoulos T, Mavroidi N, Spala G, et al. Experience of epidemiological surveillance and response for communicable diseases. In: Tsouros AD, Efstathia PA, Eds. Mass Gatherings and Public Health. The Experience of the Athens 2004 Olympic games. Copenhagen, Denmark: Ministry of Health and Social Solidarity and WHO 2007. 
[4] Tauxe RV, Hughes JM. Food-borne disease. In: Mandel GL, Bennett JE, Dolin R, Eds. Principles and practice of infectious Diseases. $5^{\text {th }}$ ed. New York: Churchill Livingstone 2000.

[5] Centers for Diseases Control. Case definitions for public health surveillance. MMWR Morb Mort Wkly Rep 1990; 39: 13.

[6] Centers for Disease Control and Prevention. Surveillance for foodborne disease outbreaks - United States, 1998-2002. MMWR Morb Mortal Wkly Rep CDC Surveill Summ 2006; 55: 1-34.

[7] Bryan FL, Guzewich JJ, Todd ECD. Surveillance of foodborne Disease III. Summary and presentation of data on vehicles and attributory factors; their value and limitations. J Food Prot 1997; 60: 701-14.

[8] Weingold SE, Guzewich JJ, Fudala JK. Use of food borne disease data for HACCP risk assessment. J Food Prot 1994; 57: 820-30.

[9] CDC. Diagnosis and management of food borne illnesses: A primer for physicians and other health care professionals. MMWR Morb Mortal Wkly Rep 2004; 53: 1-12.

[10] Parasidis T, Divari E, Fatouros N, Vantarakis A. Outbreak of acute gastroenteritis in Greece during a school excursion, April 2007. Euro Surveill 2007; 12(27): pii=3229. Available online: http://www. eurosurveillance.org/ViewArticle.aspx?ArticleId=3229

[11] Lopman B, Vennema H, Hohli E, et al. Recent increase in outbreaks of viral gasroenteritis in Europe may be related to epidemic spread of a new Norovirus variant. Lancet 2004; 363 : 682-8.

[12] Domínguez A, Torner N, Ruiz L, et al. Foodborne Salmonellacaused outbreaks in Catalonia (Spain), 1990 to 2003. J Food Prot 2007; 70: 209-13.

[13] Katrin S, Andrea G, Eds. WHO [homepage on the Internet]. WHO Surveillance programme for control of foodborne infections and intoxications in Europe. $8^{\text {th }}$ Report 1999-2000. BfR - FAO/WHO Collaborating Centre for Research and Training in Food Hygiene and Zoonoses. 2003. Available from: http://www.euro.who.int/ foodsafety/Surveillance/20031127_1

[14] Bonner C, Foley B, Wall P, Fitzgerald M. Analysis of outbreaks of infectious intestinal disease in Ireland: 1998 and 1999. Ir Med J 2001; 94: 142-4.

[15] Van Duynhoven YTHP, de Jager CM, Kortbeek LM, et al. A oneyear intensified study of outbreaks of gastroenteritis in The Netherlands. Epidemiol Infect 2005; 133: 9-21.

[16] Olsen SJ, MacKinnon LC, Goulding JS, Bean NH, Slutsker L. Surveillance for foodborne-disease outbreaks-United States, 19931997. MMWR CDC Surveill Summ 2000; 49: 1-62.

[17] Van Loock F, Ducoffre G, Dumont JM, et al. Analysis of foodborne disease in Belgium in 1997. Acta Clin Belg 2000; 55: 300-6.
[18] Galanis E, Lo Fo Wong DM, Patrick ME, et al.; World Health Organization Global Salm-Surv. Web-based surveillance and global Salmonella distribution, 2000-2002. Emerg Infect Dis 2006; 12: 381-8.

[19] Mellou K, Psichogiou M, Triantafillou E, Rostadakis D, Panagiotopoulos T. Salmonella enteritidis outbreak among participants of an official dinner, Athens, Greece, November 2003. Proceedings of the $9^{\text {th }}$ EPIET Scientific Seminar. Menorca, Spain Oct 14-16, 2004.

[20] Johansson PJ, Torvén M, Hammarlund AC, Björne U, Hedlund KO, Svensson L. Food-borne outbreak of gastroenteritis associated with genogroup I calicivirus. J Clin Microbiol 2002; 40: 794-8.

[21] Makary P, Maunula L, Niskanen T, et al. Multiple norovirus outbreaks among workplace canteen users in Finland, July 2006. Epidemiol Infect 2008; 4: 1-6.

[22] Torner N, Domínguez A, Ruíz L, et al. Catalan Viral Gastroenteritis Study Group. Acute gastroenteritis outbreaks in Catalonia, Spain: norovirus versus Salmonella. Scand J Gastroenterol 2008; 43: 567-73.

[23] Marks PJ, Vipond IB, Regan FM, Wedgwood K, Fey RE, Caul EO. A school outbreak of Norwalk-like virus: evidence for airborne transmission. Epidemiol Infect 2003; 131: 727-36.

[24] Cheesbrough JS, Green J, Gallimore CI, Wright PA, Brown DW. Widespread environmental contamination with Norwalk-like viruses (NLV) detected in a prolonged hotel outbreak of gastroenteritis. Epidemiol Infect 2000; 125: 93-8.

[25] Correia AM, Goncalves G, Saraiva MM. Foodborne outbreaks in Nothern Portugal, 2002. Euro Surveill 2004; 9: 18-20.

[26] Institute of Food Technologists' Expert Panel on Food Safety and Nutrition. Scientific status summary, foodborne illness: role of home food-handling practices. Food Technol 1995; 49: 119-31.

[27] Humphrey T. The spread and persistence of Campylobacter and Salmonella in the domestic kitchen. J Infect 2001; 43: 50-3.

[28] Batz MB, Doyle MP, Morris G Jr, et al. Food Attribution Working Group. Attributing illness to food. Emerg Infect Dis 2005; 11: 9939.

[29] Domínguez A, Broner S, Torner N, et al.; Working group for the study of outbreaks of acute gastroenteritis in Catalonia. Differential features of foodborne gastroenteritis outbreaks of known and unknown etiology. J Food Prot 2009; 72: 1958-62.

[30] Episouth: Network Network for Communicable Disease Control in Southern Europe and Mediterranean Countries. Available online: http://www.episouth.org

[31] Vorou R, Gkolfinopoulou K, Dougas G, Mellou K, Pierroutsakos I, Papadimitriou T. Local brucellosis outbreak on Thassos, Greece: a preliminary report. Euro Surveill 2008; 13. Available online: http://www.eurosurveillance.org/ViewArticle.aspx?ArticleId=18910

(C) Vorou et al.; Licensee Bentham Open.

This is an open access article licensed under the terms of the Creative Commons Attribution Non-Commercial License (http://creativecommons.org/licenses/ by-nc/3.0/) which permits unrestricted, non-commercial use, distribution and reproduction in any medium, provided the work is properly cited. 